Note

\title{
Microscale extraction method for HPLC carotenoid analysis in vegetable matrices
}

\author{
Sidney Pacheco ${ }^{1,2 *}$, Fernanda Marques Peixoto ${ }^{2}$, Renata Galhardo Borguini ${ }^{1}$, Luzimar da Silva de Mattos do Nascimento ${ }^{1}$, Claudio
} Roberto Ribeiro Bobeda ${ }^{2,3}$, Manuela Cristina Pessanha de Araújo Santiago ${ }^{1}$, Ronoel Luiz de Oliveira Godoy ${ }^{1}$

'Embrapa Food Technology, Av. das Américas, 29501, Guaratiba - 23020-470 - Rio de Janeiro, RJ - Brazil. ${ }^{2}$ Federal Rural University of Rio de Janeiro, BR 465, km 7 23890-000 - Seropédica - RJ - Brazil.

${ }^{3}$ Federal Institute of Rio de Janeiro - Campus Nilópolis, R. Lúcio Tavares, 1045, Centro - 26530-060 - Nilópolis, RJ Brazil.

Corresponding Author <sidney.pacheco@embrapa.br>

Edited by: Paulo Cesar Sentelhas

Received November 27, 2013

Accepted April 24, 2014

\begin{abstract}
In order to generate simple, efficient analytical methods that are also fast, clean, and economical, and are capable of producing reliable results for a large number of samples, a micro scale extraction method for analysis of carotenoids in vegetable matrices was developed. The efficiency of this adapted method was checked by comparing the results obtained from vegetable matrices, based on extraction equivalence, time required and reagents. Six matrices were used: tomato (Solanum lycopersicum L.), carrot (Daucus carota L.), sweet potato with orange pulp (Ipomoea batatas (L.) Lam.), pumpkin (Cucurbita moschata Duch.), watermelon (Citrullus lanatus (Thunb.) Matsum. \& Nakai) and sweet potato (Ipomoea batatas (L.) Lam.) flour. Quantification of the total carotenoids was made by spectrophotometry. Quantification and determination of carotenoid profiles were formulated by High Performance Liquid Chromatography with photodiode array detection. Microscale extraction was faster, cheaper and cleaner than the commonly used one, and advantageous for analytical laboratories.

Keywords: $\beta$-carotene, $\alpha$-carotene, lycopene
\end{abstract}

\section{Introduction}

Carotenoids belong to a family of more than 600 fat-soluble pigments that are very abundant in nature (Krinsky and Johnson, 2005). They have great nutritional interest and some of them are precursors of vitamin A, a deficiency of which is associated with night blindness, the premature death of children and xerophthalmia. Interest in these pigments has increased greatly in recent years because of their antioxidant activity that reduces the risk of developing degenerative diseases, such as cancer, cardiovascular disease and the formation of cataracts (Krinsky, 1994; Bramley, 2000; Gale et al., 2003; Delcourt et al., 2006).

Analytical and extraction procedures have been developed over the years by many authors. Identification, quantification and determination of carotenoid profiles have been performed by High Performance Liquid Chromatography (HPLC), using the reverse phase column and photodiode array detector, which allow for a continuous collection of spectrophotometric data during analysis. Prior to instrumental analysis, a critical step is the extraction of analytes from a matrix, since food matrixes are complex on account of the variety of compounds present.

Kaiser et al. (2007) developed a small-scale method for quantitation of carotenoids in bacteria and yeasts, but in this case carotenoids are embedded into a compact matrix in small concentrations. Akhtar and Bryan (2008) proposed a fast method which involved dispersion of the sample in hot water $\left(60^{\circ} \mathrm{C}\right)$, with butylated hydroxytoluene (BHT) in ethanol, followed by extraction with chloroform. However, chloroform extracts all kinds of fat-soluble compounds, so that the determination of carotenoids remains difficult. Caballo et al. (2012) pro- posed a microextraction of carotenoids using a supramolecular solvent consisting of decanoic acid assemblies to simplify carotenoid determination in farmed salmonids, but this is a specific method for ketocarotenoids. Sérino et al. (2009) suggested a microextraction of tomato carotenoids (lutein, lycopene, $\beta$-carotene, and phytoene) using sodium chloride, $\mathrm{n}$-hexane, dichloromethane, and ethyl acetate.

The demand for simple, efficient analytical methods that are also fast, clean and economical, and are also capable of producing reliable results from a large number of samples is increasing. Thus, the aim of this study was to adapt the commonly used carotenoid extraction method to a microscale extraction (MSE) method. The efficiency of the adapted method was checked by comparing the results obtained from six vegetable matrices, as regards extraction equivalence, time spent and reagents.

\section{Materials and Methods}

This work was developed in an ISO/IEC 17025:2005 Brazilian certified laboratory (INMETRO, 2011).

\section{Chemical Reagents}

All solvents were of chromatographic grade, including acetone, petroleum ether $35-60{ }^{\circ} \mathrm{C}$, methanol $(\mathrm{MeOH})$, methyl tert-butyl ether (MTBE). Carotenoid standards were extracted and purified from fruits and vegetables rich in carotenoids (Pacheco et al., 2013). The concentrations of lycopene, $\beta$-carotene and $\alpha$-carotene standards were determined spectrophotometrically using the $\mathrm{A}^{1 \%}{ }_{1 \mathrm{~cm}}$ value of 3450,2592 and 2800 , respectively, in petroleum ether. The standard purities were greater than $97 \%$. 


\section{Sample preparation}

Tomatoes (Solanum lycopersicum L.), carrots (Daucus carota L.), pumpkins (Cucurbita moschata Duch.) and watermelon (Citrullus lanatus (Thunb.) Matsum. \& Nakai) were obtained from a local market in the city of Rio de Janeiro, Brazil. Sweet potatoes with orange pulp (Ipomoea batatas (L.) Lam.) were harvested in Brasilia, Brazil. They were analyzed at two stages: as a raw sample and after processing, as flour prepared by drying and milling the potatoes. The edible parts of fresh samples (watermelon and pumpkins without the seeds) were ground in a mill at room temperature $\left(25^{\circ} \mathrm{C}\right)$ and taken for carotenoid extraction.

\section{Commonly used Extraction (CUE)}

Taken as a reference for comparison purposes, the commonly used carotenoid extraction procedure was performed as described by Rodriguez-Amaya (2001), using limited light and controlled temperature to minimize degradation and isomerization of the carotenoids. All analyses were performed in triplicate. Approximately 2 to $5 \mathrm{~g}$ of each of the six matrices were weighed and then manually macerated in a porcelain grail with $3 \mathrm{~g}$ of celite and $50 \mathrm{~mL}$ of acetone. The mixture was vacuum filtered in a glass funnel with a sintered plate. The extraction procedure was repeated three or four times until the sample no longer exhibited the characteristic color of carotenoids. The acetone extract was transferred quantitatively to a separator funnel containing $50 \mathrm{~mL}$ of petroleum ether and washed, at least three times, with $300 \mathrm{~mL}$ ultrapure water. The ether extract was filtered through anhydrous sodium sulfate, collected in $100 \mathrm{~mL}$ volumetric flasks and completed with petroleum ether. The level of total carotenoids in the sample extracts was determined by spectrophotometry at $450 \mathrm{~nm}$. Carotenoid profiles were determined by transferring a $1 \mathrm{~mL}$ aliquot of the sample extract to an amber vial, which was dried in an $\mathrm{N}_{2}$ stream and then dissolved in $100 \mu \mathrm{L}$ of acetone. Before HPLC analysis, the solution was vortexed for $10 \mathrm{~s}$.

\section{Microscale Extraction (MSE)}

Approximately $0.1 \mathrm{~g}$ of sample was weighed in a $2 \mathrm{~mL}$ microcentrifuge tube, $1 \mathrm{~mL}$ of acetone was added, and the solid residue was macerated using a microtur$\operatorname{rax}$ for $30 \mathrm{~s}$. The mixture was centrifuged at 6,339 $\mathrm{x}$ g for $1 \mathrm{~min}$ and the supernatant was transferred to a $25 \mathrm{~mL}$ burette containing $5 \mathrm{~mL}$ of solution of $5 \%$ ethyl ether in petroleum ether. The resulting supernatant (acetone extract) was transferred, quantitatively, to a burette. Attention was paid so as not to transfer the pellet formed. Acetone $(500 \mu \mathrm{L})$ was added to the residue of the centrifuge tube and the extraction procedure was repeated three or four times until the extract no longer exhibited the characteristic color of carotenoids. Then the extract was washed three times using ultrapure water or until the wash water became translucent. The extract was allowed to stand for $3 \mathrm{~min}$ before water decantation.
The volume of ether extract was recorded (up to second decimal number), then $1 \mathrm{~mL}$ was transferred to a volume cuvette and the total carotenoid contents were determined by spectrophotometry, as above. Carotenoid profiles were determined as described in CUE. All analyses were performed in triplicate.

\section{Recovery test}

For the recovery study, the Standard Reference Material ${ }^{\circledR}$ (SRM 3280) from the National Institute of Standards and Technology (NIST) was used. This material consists of Multivitamin and Multielement Tablets that are intended primarily for use in validating analytical methods for the determination of vitamins, carotenoids, and mineral elements in dietary supplement tablets and similar matrices. This SRM can also be used for quality assurance when assigning values to in-house control materials. The SRM was extracted using both CUE and MSE procedures. The results were expressed in percentage of recovery.

\section{HPLC Analysis}

Profiles of the carotenoids were determined in an acetone extract by HPLC (Pacheco et al., 2012), using a Waters ${ }^{\mathrm{TM}}$ HPLC system, controlled by the Empower software program with the column oven at $33{ }^{\circ} \mathrm{C}$ and photodiode array detector (PDA). Carotenoid separation was obtained in a $\mathrm{C}_{30}$ column (S-3 Carotenoid, $4.6 \mathrm{~mm}$ $\times 250 \mathrm{~mm}, \mathrm{YCM}^{\mathrm{TM}}$ ) by a gradient elution of methanol and methyl tert-butyl ether. The elution started with a mix of $80 \%$ methanol and $20 \%$ methyl tert-butyl ether. At $0.5 \mathrm{~min}$ the ether concentration was increased to 25 $\%$, at $15.00 \mathrm{~min}$ to $85 \%$ and at 15.05 to $90 \%$ ether. The ether concentration was maintained at $90 \%$ until 16.50 min and then at 16.55 min returned to the initial condition $(20 \%)$, remaining constant up to the $28 \mathrm{~min}$. point.

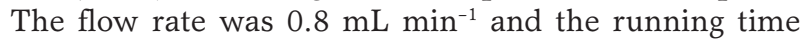
was $28 \mathrm{~min}$. The injection volume of the samples was 15 $\mu \mathrm{L}$. Carotenoids were identified based on their retention times and UV/Vis absorption spectra, compared to the retention times of the carotenoid standards.

\section{Statistical Analysis}

Total carotenoids, $\beta$-carotene, $\alpha$-carotene and lycopene contents and data from the two extraction methods were compared by calculating the average, variance, $\mathrm{p}$ value, and F-statistic between and within groups. Statistical analysis was performed at $p<0.05$. The mean values of the release rates were compared using analysis of variance (ANOVA) and F-test for comparisons of two extraction methods of $\beta$-carotene, $\alpha$-carotene, lycopene and total carotenoids from six matrices.

\section{Results and Discussion}

Recovery values were calculated based on the SMR 3280 results for total carotenoids $\left(514 \mu \mathrm{g} \mathrm{g}^{-1}\right)$. For CUE the recovery was $92 \%\left(477.2 \mu \mathrm{g} \mathrm{g}^{-1}\right.$ of total carot- 
Table 1 - Carotenoid (all-trans- $\beta$-carotene, $\alpha$-carotene and lycopene) concentrations and total carotenoid content from six matrices, obtained by commonly used and microscale extraction methods.

\begin{tabular}{|c|c|c|c|c|c|c|}
\hline & Extraction Type & All-trans- $\beta$-carotene & $\alpha$-carotene & Lycopene & $\begin{array}{c}\text { Total } \\
\text { Carotenoid }\end{array}$ & $\begin{array}{c}\text { Total } \\
\text { Carotenoid }\end{array}$ \\
\hline & & 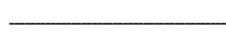 & $-\mu \varepsilon$ & + & - & $\mathrm{CV}(\%)^{*}$ \\
\hline \multirow{2}{*}{ Carrot } & MSE & $58.3 \pm 1.4^{\mathrm{a}}$ & $46.0 \pm 1.1^{\mathrm{a}}$ & - & $106.0 \pm 2.6^{\mathrm{a}}$ & 2 \\
\hline & CUE & $57.1 \pm 0.4^{\mathrm{a}}$ & $45.0 \pm 0.3^{\mathrm{a}}$ & - & $110.0 \pm 0.7^{\mathrm{a}}$ & 1 \\
\hline \multirow{2}{*}{ Orange pulp sweet potato } & MSE & $85.0 \pm 3.1^{\mathrm{b}}$ & $4.0 \pm 0.1^{b}$ & - & $95.0 \pm 3.5^{b}$ & 4 \\
\hline & CUE & $85.0 \pm 2.0^{b}$ & $4.0 \pm 0.1^{b}$ & - & $95.0 \pm 2.2^{b}$ & 2 \\
\hline \multirow{2}{*}{ Pumpkin } & MSE & $98.4 \pm 3.6^{c}$ & $121.0 \pm 4.5^{c}$ & - & $230.0 \pm 8.5^{c}$ & 4 \\
\hline & CUE & $74.0 \pm 0.9 c$ & $98.0 \pm 1.2^{c}$ & - & $212.0 \pm 2.6^{c}$ & 1 \\
\hline \multirow{2}{*}{ Watermelon } & MSE & $13.0 \pm 0.5^{d}$ & $3.0 \pm 0.1^{\mathrm{d}}$ & $33.0 \pm 1.2^{\mathrm{d}}$ & $56.0 \pm 2.1^{\mathrm{d}}$ & 4 \\
\hline & CUE & $13.0 \pm 0.2^{\mathrm{d}}$ & $3.0 \pm 0.0^{d}$ & $28.0 \pm 0.3^{d}$ & $56.0 \pm 0.7^{d}$ & 1 \\
\hline \multirow{2}{*}{ sweet potato flour } & MSE & $331.0 \pm 7.4^{\mathrm{e}}$ & $17.0 \pm 0.4^{e}$ & - & $392.0 \pm 8.8^{e}$ & 2 \\
\hline & CUE & $273.0 \pm 7.5^{\mathrm{e}}$ & $14.0 \pm 0.4^{e}$ & - & $312.0 \pm 8.5^{e}$ & 3 \\
\hline \multirow{2}{*}{ Tomato } & MSE & $5.0 \pm 0.2^{f}$ & $4.0 \pm 0.1^{\dagger}$ & $28.0 \pm 0.8^{f}$ & $43.0 \pm 1.3^{\dagger}$ & 3 \\
\hline & CUE & $4.1 \pm 0.1^{\dagger}$ & $4.0 \pm 0.1^{f}$ & $25.0 \pm 0.6^{f}$ & $38.0 \pm 0.9^{\dagger}$ & 2 \\
\hline \multirow{2}{*}{ SMR 3280} & MSE & $307.6 \pm 13.2$ & - & - & $535.0 \pm 23.0$ & 4 \\
\hline & CUE & $279.2 \pm 9.5$ & - & - & $477.2 \pm 16.2$ & 3 \\
\hline
\end{tabular}

MSE-Microscale extraction; CUE- Commonly used extraction; ${ }^{*}$ Mean of replicates $(n=3)$; CV- Coefficient of variation; SRM 3280- Standard Reference Material. Same letters between rows for each matrix mean that there was no difference between extraction $(p<0.05)$.

enoids) and for MSE $104 \%$ (535.0 $\mathrm{\mu g} \mathrm{g}^{-1}$ of total carotenoids). Results of all-trans- $\beta$-carotene, $\alpha$-carotene, and lycopene contents obtained using both extraction methods are shown in Table 1. The carotenoid levels for all analyzed matrices were as per the Brazilian database on food carotenoids (Rodriguez-Amaya et al., 2008) and the applied carotenoid extraction methods were equivalent, since there was no difference between results (Table 1).

Analysis of variance (ANOVA) showed that variances of both methods were no different $(p<0.05)$. For the assessment of the precision of the proposed method, the coefficient of variation $(\mathrm{CV})$ of total carotenoids was calculated (Table 1) and results had low variation (below $5 \%$ ) among triplicates for each matrix, but CV for the MSE method was slightly higher than for the conventional one. This may be understandable because the micro scale extraction method uses low sample amounts. It is thus noteworthy that sample homogenization is a critical step.

Niizu and Rodriguez-Amaya (2005) analyzed carotenoids by HPLC in Brazilian vegetables: Nantes carrot (Daucus carota L.), chicory (Cichorium intybus L.), Boston and curly lettuce (Lactuca sativa L.), green bell pepper (Capsicum annum L.), arugula (Eruca sativa Mill.), Carmen tomato (Solanum lycopersicum L.) and Cress (Lepidium sativum L.), and they reported a mean of $35.0 \mathrm{\mu g} \mathrm{g}^{-1}$ of $\alpha$-carotene and $61.5 \mathrm{\mu g} \mathrm{g}^{-1}$ of $\beta$-carotene for carrot and $35.4 \mathrm{\mu g} \mathrm{g}^{-1}$ of lycopene and $3.2 \mathrm{\mu g} \mathrm{g}^{-1}$ of $\beta$-carotene in tomatoes. For Brazilian pumpkin, Carvalho et al. (2012) found $234.2 \mu \mathrm{g} \mathrm{g}^{-1}$ of total carotenoids, $73.0 \mu \mathrm{g} \mathrm{g}^{-1}$ of $\alpha$ carotene and $141.9 \mu_{\mathrm{g} \mathrm{g} \mathrm{g}^{-1}}$ of $\beta$-carotene. These values are similar to those of the present study and show the equivalence of the MSE.
Table 2 - Sample amount and reagent consumption per analysis in microscale and commonly used extraction methods of carotenoids.

\begin{tabular}{lccc}
\hline Reagent & $\begin{array}{c}\text { Microscale } \\
\text { extraction }\end{array}$ & $\begin{array}{c}\text { Commonly used } \\
\text { extraction }\end{array}$ & Reduction (\%) \\
\hline Sample amount & $0.1 \mathrm{~g}$ & $2-5 \mathrm{~g}$ & $>95$ \\
Acetone & $4 \mathrm{~mL}$ & $300 \mathrm{~mL}$ & 99 \\
Petroleum ether & $10 \mathrm{~mL}$ & $100 \mathrm{~mL}$ & 90 \\
Celite & $0 \mathrm{~g}$ & $6 \mathrm{~g}$ & 100 \\
Sodium sulfate & $0 \mathrm{~g}$ & $3 \mathrm{~g}$ & 93 \\
Milli-Q water & $50 \mathrm{~mL}$ & $1800 \mathrm{~mL}$ & 97 \\
\hline
\end{tabular}

Figure 1 shows three chromatograms and UV-Vis spectrum obtained for all-trans- $\beta$-carotene and $\alpha$-carotene analysis for pumpkin, sweet potato flour and carrot. The chromatographic profile was similar for both extractions as expected. The time required for extraction was an important advantage of the method. Microscale extraction was faster than commonly used, since it took about $8 \mathrm{~min}$ per extraction instead of $50 \mathrm{~min}$ per the commonly used extraction, which corresponded to an $84 \%$ reduction in time required. For the routines performed in an analytical laboratory, it represents excellent savings in terms of time, employees and money. Also, acetone and petroleum ether consumption were reduced by $99 \%$ and $90 \%$, respectively, and the use of celite and sodium sulfate was eliminated (Table 2). These numbers represent a great reduction in the cost of analysis thanks to a minimum use of reagents and residue production that imply high costs for suitable treatment. Currently efforts are underway in many laboratories to develop cheaper and cleaner methodologies for rapid and accurate determinations. 

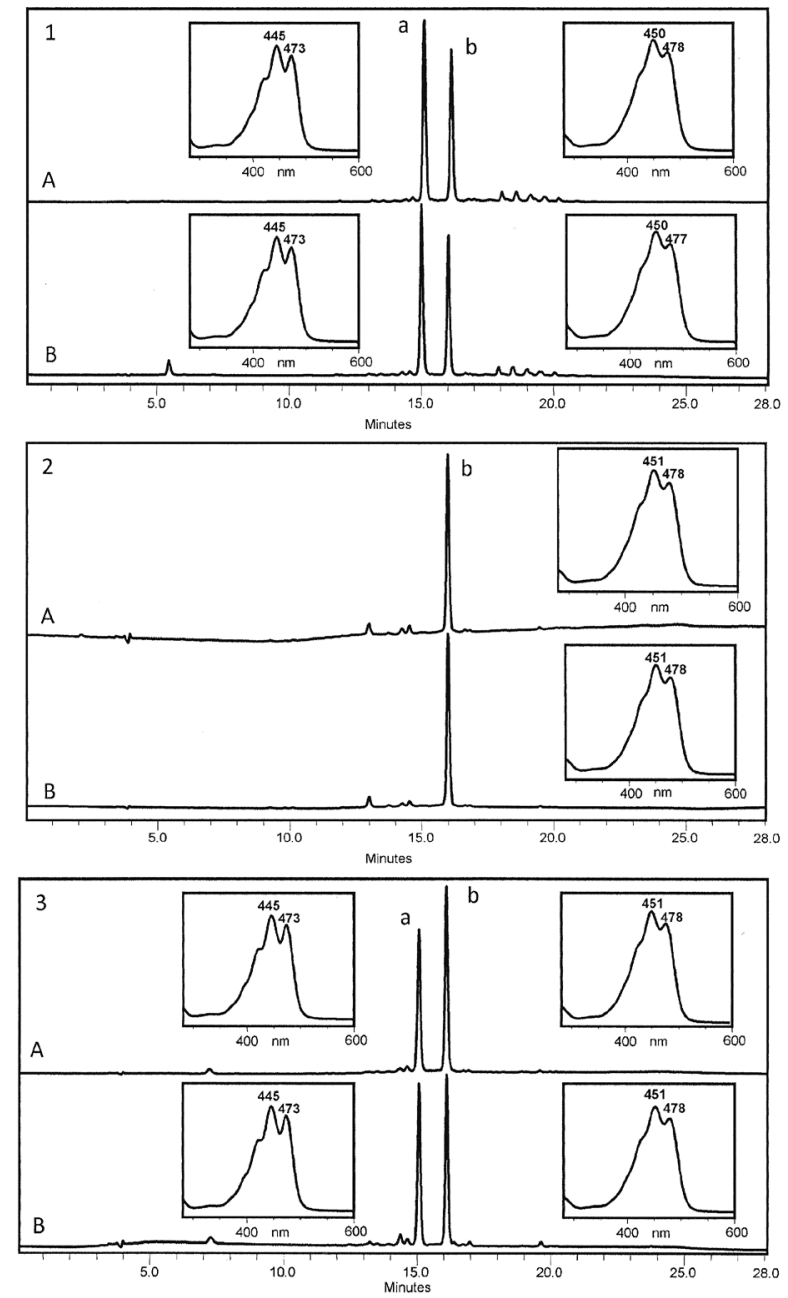

Figure 1 - HPLC chromatograms and UV-Vis spectrum of three matrices: pumpkin (1), sweet potato flour (2) and carrot (3) of (A) microscale extraction and (B) commonly used extraction. Peak identification: a) $\alpha$-carotene; b) All-trans- $\beta$-carotene.

\section{References}

Akhtar, M.H.; Bryan, M. 2008. Extraction and quantification of major carotenoids in processed foods and supplements by liquid chromatography. Food Chemistry 111: 255-261.

Bramley, P.M. 2000. Is lycopene beneficial to human health? Phytochemistry 54: 233-236.

Caballo, C.; Costi, E.M.; Sicilia, M.D.; Rubio, S. 2012. Determination of supplemental feeding needs for astaxanthin and canthaxanthin in salmonids by supramolecular solventbased microextraction and liquid chromatography-UV/VIS spectroscopy. Food Chemistry 13: 1244-1249.
Carvalho, L.M.J.; Gomes, P.B.; Godoy, R.L.O.; Pacheco, S.; Monte, P.H.F.; Carvalho, J.L.V.; Nutti, M.R.; Neves, A.C.L.; Vieira, A.C.R.A.; Ramos, S.R.R. 2012. Total carotenoid content, $\alpha$-carotene and $\beta$-carotene, of landrace pumpkins (Cucurbita moschata Duch): a preliminary study. Food Research International 47: 337-340.

Delcourt, C.; Carrière, I.; Delage, M.; Barberger-Gateau, P.; Schalch, W. 2006. Plasma lutein and zeaxanthin and other carotenoids as modifiable risk factors for age-related maculopathy and cataract: the POLA study. Investigative Ophthalmology \& Visual Science 47: 2329-2335.

Gale, C.R.; Hall, N.F.; Phillips, D.I.W.; Martyn, C.N. 2003. Lutein and Zeaxanthin status and risk of age-related macular degeneration. Investigative Ophthalmology \& Visual Science 44: 2461-2465.

Instituto Nacional de Metrologia [INMETRO]. 2011. Guidance of validation methods of chemical testing. Inmetro, Brasília, DF, Brazil (DOC-CGCRE-008: 24).

Kaiser, P.; Surmann, P.; Vallentin, G.; Fuhrmann, H.V.J. 2007. A small-scale method for quantitation of carotenoids in bacteria and yeasts. Journal of Microbiological Methods 70: 142-149.

Krinsky, N.I. 1994. The biological properties of carotenoids. Pure and Applied Chemistry 66: 1003-1010.

Krinsky, N.I.; Johnson, E.J. 2005. Carotenoid actions and their relation to health and disease. Molecular Aspects of Medicine 26: 459-516.

Niizu, P.Y.; Rodriguez-Amaya, D.B. 2005. New data on the carotenoid composition of raw salad vegetables. Journal of Food Composition and Analysis 18: 739-749.

Pacheco, S.; Godoy, R.L.O.; Porte, A.; Rosa, J.S.; Santiago, M.C.P.A. 2012. Obtaining cis-lycopene and $\beta$-criptoxanthin standards for high performance liquid chromatography from bitter melon and persimmon. Unopar Científica Ciências Biológicas e da Saúde 14: 81-86 (in Portuguese, with abstract in English).

Pacheco, S.; Godoy, R.L.O.; Peixoto, F.M.; Gouvêa, A.C.M.S.; Santiago, M.C.P.A.; Felberg, I.; Borguini, R.G. 2013. Preparation of high purity analytical standards using high performance liquid chromatography in analytical scale. Analytical Chemistry 12: 194-197.

Rodriguez-Amaya, D.B. 2001. A Guide to Carotenoid Analysis in Foods. Ilsi Press, Washington, DC, USA.

Rodriguez-Amaya, D.B.; Kimura, M.; Godoy, H.T.; Amaya-Farfan, J. 2008. Updated Brazilian database on food carotenoids: factors affecting carotenoid. Journal of Food Composition and Analysis 21: 445-463.

Sérino, S.; Gomez, L.; Costabliola, G.; Gautier, H. 2009. HPLC assay of tomato carotenoids: validation of a rapid microextraction technique. Journal of Agricultural and Food Chemistry 57: 8753-8760. 